\title{
Suicidal Ideation among Depressed People Living with HIV/AIDS in Nigeria, West Africa
}

\author{
Rasaki O. Shittu1, Moradeyo K. Alabi², Louis O. Odeigah², Musa A. Sanni' ${ }^{3}$, Baba A. Issa4, \\ Abdulganiyu T. Olanrewaju ${ }^{4}$, Abdullateef Gbenga Sules, Sunday A. Aderibigbe 6 \\ ${ }^{1}$ Department of Family Medicine, Kwara State Specialist Hospital, Ilorin, Nigeria \\ ${ }^{2}$ Department of Family Medicine, University of Ilorin Teaching Hospital, Ilorin, Nigeria \\ ${ }^{3}$ Department of Haematology, Kwara State Specialist Hospital, Ilorin, Nigeria \\ ${ }^{4}$ Department of Behavioural Sciences, University of Ilorin Teaching Hospital, Ilorin, Nigeria \\ ${ }^{5}$ Department of Family Medicine, Ahmadu Bello University, Teaching Hospital, Zaria, Nigeria \\ ${ }^{6}$ Department of Epidemiology and Community Health, University of Ilorin Teaching Hospital, Ilorin, Nigeria \\ Email: oorelopehospital@gmail.com, moradalabi@yahoo.com, lodeigah@yahoo.com, \\ maskareem2009@yahoo.com, issababa2002@yahoo.com, laromoye554@yahoo.com, gbensule@yahoo.com, \\ tayonov23@yahoo.com
}

Received 13 March 2014; revised 13 April 2014; accepted 20 April 2014

Copyright (C) 2014 by authors and Scientific Research Publishing Inc.

This work is licensed under the Creative Commons Attribution International License (CC BY).

http://creativecommons.org/licenses/by/4.0/

(c) (i) Open Access

\section{Abstract}

Objective: Transient suicide thoughts are common to some people throughout the course of HIV disease and often do not indicate significant risk of suicide. However, persistent suicidal thoughts with associated feelings of hopelessness and intent to die are very serious and must be assessed promptly and carefully. The aim of this study, therefore, was to examine the relationship between depression, hopelessness, psychosocial stressors and suicidal ideation in PLWHAs. Methods: This was a hospital based, cross sectional, descriptive study, of one hundred and seventy depressed adult HIV/AIDS patients of Kwara State Specialist Hospital, Ilorin. Depression and suicidal assessment were evaluated using the PHQ-9 scale. A score of $>9$ or any affirmative response to question 9 of the PHQ-9 scale necessitated suicidal risk assessment. The social determinant questionnaire was used to evaluate social cohesion and negative life events. Results: The prevalence of depression among the HIV/AID patient was $56.7 \%$. Twenty nine $(17.1 \%)$ were hopeless, twenty eight $(16.5 \%)$ had at one time or the other thought of taking their lives, six $(3.5 \%)$ had plan to take their lives. There was strong statistical association between depression, hopelessness (p-value $=0.000)$ thought of taking life $(p$-value $=\mathbf{0 . 0 0 0})$ and plan to take their lives $(p$-value $=0.030)$. Conclusion: The significant correlations between hopelessness, depression and suicidal ideation are important markers that should alert clinicians to underlying suicide risk in HIV-positive patients. In addition, low social cohesion and stressful life events were found to be risk factors for depression and suicide. Clinicians should routinely enquire about suicidality in PLWHAs to assist early diagnosis and intervention. 


\section{Keywords}

\section{Suicidal Ideation, Depression, HIV/AIDS, Nigeria, West Africa}

\section{Introduction}

Suicidal ideation is thought about or an unusual preoccupation with suicide. The range of suicidal ideation varies greatly from fleeting to detailed planning, self-harm and unsuccessful attempts, which may be deliberately constructed to fail or be discovered, or may be fully intended to result in death. Although, most people who undergo suicidal ideation do not go on to make suicide attempts, a significant proportion do [1]. Suicidal ideation is more common that suicide attempts or completed suicide [2]. To assess patients for suicide risk, warning signs and assess for risk and protective factors are pertinent. The warning signs are, threatening to hurt or kill self, or looking for ways to kill self, hopelessness, increasing alcohol or drug abuse, withdrawal from friends, family or society. Factors that may increase risk for suicide are alcohol abuse or previous history of psychiatric diagnosis and negative life events. Factors that may decrease risk for suicide are positive social support and social cohesion [3] [4].

Globally, approximately one million people kill themselves every year [5]. The WHO estimates that, by the year 2020, the worldwide incidence of suicide will reach approximately 1.53 million people, and 10 and 20 times as many individuals will attempt suicide. This global projection indicates that, suicidal behaviours constitute a significant public health problem [6]. Besides, it has been established that depressive disorders, a major cause of suicides, hitherto thought to be rare in Africa, are now recognized to be fairly common. Studies in Africa have reported high rates of depressive symptoms and suicidal behaviour in HIV-infected patients. In Ife, Nigeria, rates were found to be 0.4 per 100,000 populations [3].

While suicidal ideation had been extensively studied in the general population [5] [7], its relationship with HIV infection was less well documented. This is of concern, since the psychological responses to an HIV-positive result can be wide ranging and include feeling hopelessness, anxiety, worthlessness and depression and suicidal behaviour [8] [9]. Recognizing this, in a bio-psychosocial context, is paramount to understanding the relationship between the HIV/AIDS pandemic and increased prevalence of suicidal behavior [9]. Research [10] [11] suggests that people who are HIV positive may be at greater risk for suicide than their uninfected counterparts. HIV/AIDS had been recognized as a predictor of suicidality [12]. In a study of more than 2300 psychiatric consultations in New York City Hospital, approximately 20 percent of patients with HIV infection exhibited suicidal behavior compared with 14 percent of patients with unknown HIV sero-status [13]. Person with HIV infection who attempted suicide were likely to abuse drugs, experience social isolation, and lack social support [14] [15]. Seth and colleagues [16] found out that $27 \%$ of respondents reported having thought about taking their own life. This was similarly to the findings of Kalichman [17]. In Nigeria, Gali and colleagues while presenting suicide attempts in HIV/AIDS patients reported two cases of penetrating abdominal injuries with visceral injuries, that were repaired at laparatomy [18].

The association between hopelessness, depression and suicide has been well documented. [7] Hopelessness, being a feeling of despair and extremely pessimism about the future, forms part of PHQ-9 questionnaire of depression. Central to depression are negative thoughts generated by dysfunctional beliefs, which in part may trigger suicidal behaviour in HIV-positive patients [9].

Finding from psychology autopsy studies had consistently indicated that more than 9 percent of completed suicides in all age groups are associated with psychiatric disorder [6]. It is not the psychiatric disorder itself that increases the risk of completed suicide, but the combination of the psychiatric disorder and a stressor like HIV/AIDS.

Although 80 percent of persons who commit suicide were men [6], majority of those who made non-fatal suicide attempts were women between 25 and 44 years of age [19]. Similarly, Rosengad and co-workers found out that HIV-positive men were at greater risk for suicide than women [20].

Previous studies had identified social isolation, lack of social support and stressful live events as prominent risk factors and indications for suicidal behaviour in PLWAs. However, results from previous studies comparing the rates of suicidal thought and behavior among PLWAs had been conflicting and inconsistent. These studies 
were performed before the advent of free HAART, when the prognosis of People with HIV was much poorer. Furthermore, there is a paucity of data on the suicidal ideation among PLWHAs in Nigeria in general, and North central in particular. It is against this backdrop, that the present study aimed to explore the relationship between hopelessness, depression and suicidal ideation among PLWHAs.

\section{Methods}

This study was conducted at a designated HIV/AIDS treatment centre located in the North Central Nigeria. Eight hundred patients had been enrolled and over six hundred were on Highly Active Antiretroviral Therapy (HAART). The centre is currently being founded by a Non-Governmental Organization (NGO), Friends for Global Health.

This study was a descriptive, cross-sectional study carried out from $1^{\text {st }}$ of April to $15^{\text {th }}$ July, 2013. The inclusion criteria were all concerted depressed HIV positive patients, who presented at the clinic. The exclusion criteria were the critically ill patients.

The sample size was estimated using the Fisher formular [21], using 21.3\% from a previous study [22], as the best estimate of depressive disorders among PLWAs. A minimum size of 218 was calculated using Fisher's formula but 300 was used to increase the power and reliability of the study. Pretesting was carried out at the Kwara State Civil Service Hospital, using 30 respondents (10\% of the sample size).

Ethical approval was obtained from the Ethical Review Committee of the Kwara State Ministry of Health before commencement of the study. An interviewer administered questionnaire was used.

The prevalence of depressive disorders and suicidal assessment among HIV/AIDS patients were assessed using the PHQ-9 scale (Appendix A). The Patients Health Questionnaire (PHQ-9) [23] is a brief, 9-item, patients self-report depression assessment tool that was derived from the interview-based PRIME-MD [24]. It was specifically developed for use in primary care general medical settings. It is the only short self-report tool that can reasonably be used both for diagnosis of DSM-4 major depression as well as for tracking of severity of major depression over time [25]. Psychometric evaluation of the PHQ-9 revealed a sensitivity ranging from $62 \%-92 \%$ and a specificity between $74 \%-88 \%$.

Respondent also completed the social determinant of depression questionnaire to access the social cohesion (Appendix B) [26]-[28]. Based on existing research [26]-[28], we used three key SDH: socioeconomic status, social cohesion and negative life events (Appendix B). Socioeconomic status included two indicators: years of schooling and self-reported economic status of the family, in general, in the previous year. Categories for years of schooling were as follows: above average ( 7 years and above), average ( $1-6$ years) and below average ( 0 years). Economic status of the family was self-reported as good, average or poor.

Social cohesion was assessed from responses to two questions: (1) in the previous year, how often did you ask someone for help when you had problems? $($ Never $=1$; Seldom $=2$; Sometimes $=3$; Often $=4)$, and when you had problems? (spouse or lover; parents, brothers, sisters or children; other relatives; people outside the family; organization or schools with whom you are affiliated; government, party or trade unions; religious or non-governmental organizations; other organizations) $($ no $=0$; yes $=1)$.

Negative life events were gauge using a 12-item scale (serious illness in oneself, serious illness in the family, financial difficulties, conflict with spouse, conflict with other family members, conflict with people in the village, conflict between family members, infertility issues, problems at work or school, problems in an intimate relationship, abuse and other events). Completed questionnaire and measurements were entered into a computer data base.

Age, gender, marital status, education level, self-rated financial status, social cohesion, employment status and estimated monthly income were the socio-demographic variables. Monthly income was assessed using the minimum wage stipulated by the Federal Government of Nigeria, which is Twenty Thousand Naira (N20,000).

Completed questionnaire and measurements were entered into a computer data base. The data were analyzed using the epidemiological information (Epi-info) 2005 software package. The 2 by 2 contingency tables were used to carry out Chi-square test and to find out the level of significance and values less than 0.05 were regarded as statistically significant.

\section{Results}

Table 1 shows the socio-demographic characteristics of the respondents. A total of one hundred and seventy sero- 
Table 1. Socio-demographic characteristics of respondents.

\begin{tabular}{|c|c|c|c|}
\hline Variable & $N=170$ & (\%) & \\
\hline \multicolumn{4}{|l|}{ Age group (years) } \\
\hline$<26$ & 19 & 11.2 & \\
\hline $26-30$ & 27 & 15.9 & \\
\hline $31-35$ & 20 & 11.8 & \\
\hline $36-40$ & 50 & 29.4 & Mean age is $39 y$ with \\
\hline $41-45$ & 11 & 6.5 & $\mathrm{SD}$ of \pm 10.8 \\
\hline $46-50$ & 19 & 11.1 & \\
\hline $51-55$ & 6 & 3.5 & \\
\hline $56-60$ & 11 & 6.5 & \\
\hline$>60$ & 7 & 4.1 & \\
\hline \multicolumn{4}{|l|}{ Gender } \\
\hline Male & 31 & 18.2 & \\
\hline Female & 139 & 81.8 & \\
\hline \multicolumn{4}{|l|}{ Ethnicity } \\
\hline Hausa & 39 & 22.9 & \\
\hline Yoruba & 92 & 54.1 & \\
\hline Igbo & 28 & 16.5 & \\
\hline Others & 11 & 6.5 & \\
\hline \multicolumn{4}{|l|}{ Religion } \\
\hline Christianity & 30 & 17.6 & \\
\hline Islam & 139 & 81.8 & \\
\hline Traditional & 1 & 0.6 & \\
\hline \multicolumn{4}{|l|}{ Marital Status } \\
\hline Single & 14 & 8.2 & \\
\hline Married & 14 & 8.2 & \\
\hline Separated/Divorced & 116 & 68.3 & \\
\hline Widowed/Widower & 26 & 15.3 & \\
\hline \multicolumn{4}{|l|}{ Educational level } \\
\hline Non-Formal & 56 & 32.9 & \\
\hline Primary & 55 & 32.4 & \\
\hline Secondary & 42 & 24.7 & \\
\hline Tertiary & 17 & 10.0 & \\
\hline \multicolumn{4}{|l|}{ Occupation } \\
\hline Trader & 91 & 53.5 & \\
\hline Civil servant & 16 & 9.4 & \\
\hline Self employed & 43 & 25.4 & \\
\hline Unemployed & 14 & 8.2 & \\
\hline Students & 6 & 3.5 & \\
\hline \multicolumn{4}{|l|}{ Monthly Income } \\
\hline No Income & 20 & 11.8 & \\
\hline$\leq 20000$ & 129 & 75.9 & \\
\hline $20001-30000$ & 10 & 5.8 & \\
\hline $30001-40000$ & 6 & 3.5 & \\
\hline $40001-50000$ & 3 & 1.8 & \\
\hline$>50000$ & 2 & 1.2 & \\
\hline
\end{tabular}

positive respondents with depression were recruited to the study. The age range 36 - 40 years, had the highest number of respondents 50 (29.4\%). Females 139 (81.8\%), outnumbered males $31(18.2 \%)$ giving a male: female ratio of 1:4.5. Predominantly, $139(81.8 \%)$ were Muslims, why Christian constituted 30 (17.6\%). One hundred and sixteen $(68.3 \%)$ were separated/divorce while $26(15.3)$, were widow/widower. The majority of them 56 (32.9\%), had no formal education, Majority, 91 (53.5\%), were traders, while 14 (8.2\%), were unemployed. Six (3.5\%) were students.

Table 2 displays the association between hopelessness and depression. Twenty nine (17.1\%) were hopeless, while $141(82.9 \%)$ were not. The association between feeling hopeless and depressed was statistically significant (p-value $=0.000)$.

Table 3 shows the association between thought of taking one's life and depression. Twenty eight (16.5\%) had at one time or the other thought of taking their life, while $142(83.5 \%)$ did not. The association between thought of taking life and depression was statistically significant ( $\mathrm{p}$-value $=0.000$ ).

Table 4 shows the association between plan to take life and depression. Six (3.5\%) had plan to take their lives, 
Table 2. Association between feeling hopeless and depression.

\begin{tabular}{|c|c|c|c|c|}
\hline \multirow{2}{*}{ feeling hopeless } & \multicolumn{2}{|c|}{ depressed } & \multirow{2}{*}{ total } & \multirow[b]{2}{*}{ p-value } \\
\hline & yes $(\%)$ & no (\%) & & \\
\hline yes & $29(17.1)$ & $0(0.0)$ & $29(9.7)$ & 0.000 \\
\hline no & $141(82.9)$ & $130(100.0)$ & $271(90.3)$ & \\
\hline total & $170(100.0)$ & $130(100.0)$ & $300(100.0)$ & \\
\hline
\end{tabular}

Table 3. Association between thought of taking life and depression.

\begin{tabular}{ccccc}
\hline \multirow{2}{*}{ thought of taking life } & \multicolumn{2}{c}{ depressed } & total & p-value \\
\cline { 2 - 3 } & yes $(\%)$ & no $(\%)$ & $28(9.3)$ & 0.000 \\
yes & $28(16.5)$ & $0(0.0)$ & $272(90.7)$ & \\
no & $142(83.5)$ & $130(100.0)$ & $300(100.0)$ & \\
\hline
\end{tabular}

Table 4. Association between plan to take life and depression.

\begin{tabular}{|c|c|c|c|c|}
\hline \multirow{2}{*}{ plan to take life } & \multicolumn{2}{|c|}{ depressed } & \multirow{2}{*}{ total } & \multirow[b]{2}{*}{ p-value } \\
\hline & yes $(\%)$ & no $(\%)$ & & \\
\hline yes & $6(3.5)$ & $0(0.0)$ & $6(2.0)$ & 0.030 \\
\hline no & $164(96.5)$ & $130(100.0)$ & $294(98.0)$ & \\
\hline total & $170(100.0)$ & $130(100.0)$ & $300(100.0)$ & \\
\hline
\end{tabular}

while $164(96.5 \%)$ were still optimistic. This is of statistical importance (p-value $=0.03)$.

Table 5 shows the association between social cohesion and depression among the respondents. The Social Cohesion was very low in both males and females, $21(67.7 \%)$ and $112(80.6 \%)$ respectively among the depressed HIV patients. Only $2(6.5 \%)$ males had high social cohesion. This was statistically significant (p-value $=$ $0.005)$.

Table 6 shows that negative life events was strongly associated with depression. Twenty-two (70.9\%) males and $62(44.6 \%)$ females had one or two negative live events whereas $9(29.1 \%)$ males and 45 (32.3\%) female's respondents had more than three negative life events. This was of statistical importance ( $p$-value $=0.004)$.

\section{Discussion}

One hundred and seventy (56.7\%) satisfied the criteria for a depressive disorder using the PH-9 score. The findings in this study confirmed those of earlier studies [29] [30] that many HIV-positive patients have high levels of depressive symptomatology, as well as the fact that those with suicidal ideation reported increased levels of such symptoms. PHQ-9 questionnaire of depression was used to contextualize this relationship, because the cognitive symptoms of depression tend to precede the affective and mood components of the disorder, which in turn are triggered by negative automatic thoughts in suicidal behaviour.

The association between feeling hopeless and depressed was statistically significant. Hopelessness is a primary mediator that links depression and suicidal ideation, and the more hopeless the individual feels about the future, the more depressed they are likely to become, unless appropriate interventions are implemented.

Some of the HIV-positive patients in this study felt that the future was blink, irrespective of whether or not they had suicidal ideation, hence this can be yardsticks that can be used by less highly trained health professionals for screening purposes at VCT clinics, and thus be used in treatment strategies to help prevent suicidal behaviour in these patients. The value obtained for patients with suicidal thought, hopelessness and plan to take life is comparable to the study of Haller and colleagues [31] [32] while studying suicidal ideation among psychiatric morbidity. The association between thought of taking life and depression was statistically significant. April and colleagues [33] reported that $79 \%$ of participants reported no thoughts of suicide. $20 \%$ reported suicidal thoughts but no intent to commit suicide, and less that $2 \%$ reported a current suicide attempt [33]. Similarly, in the study conducted at the specialty HIV clinic at a tertiary care center of South India, 20\% expressed suicidal idea- 
Table 5. Association between social cohesion and depression among HIV patients at Kwara State Specialist Hospital, Sobi, Ilorin.

\begin{tabular}{cccccc}
\hline & \multicolumn{3}{c}{ Social Cohesion } & Total \\
\cline { 2 - 5 } Depression & Low & Fair & $\begin{array}{c}\text { High } \\
6-9\end{array}$ & p-value \\
\hline Depressed Male & $21(67.7)$ & $8(25.9)$ & $2(6.5)$ & $31(100)$ & 0.005 \\
Depressed Female & $112(80.6)$ & $27(19.4)$ & $0(0.0)$ & $139(100)$ & \\
\hline
\end{tabular}

Table 6. Association between negative life events and depression among HIV patients at Kwara State Specialist Hospital, Sobi, Ilorin.

\begin{tabular}{|c|c|c|c|c|c|c|}
\hline \multirow[b]{2}{*}{ Depression } & \multicolumn{4}{|c|}{ Negative Life Events } & \multirow[b]{2}{*}{ Total } & \multirow[b]{2}{*}{ p-value } \\
\hline & 0 & 1 & 2 & $3-9$ & & \\
\hline Depressed Male & $0(0.0)$ & $17(54.8)$ & $5(16.1)$ & $9(29.1)$ & $31(100.0)$ & 0.004 \\
\hline Depressed Female & $32(23.0)$ & $33(23.7)$ & 29 (20.9) & $45(32.3)$ & $139(100.0)$ & \\
\hline
\end{tabular}

tion, and $6 \%$ reported persistent suicidal ideations, whereas $8 \%$ had made attempts to commit suicide [34]. In Spain, Carvajai and colleagues [35] assessed 442 HIV-infected patients for suicidality, 5 patients had suicidal thought, 5 had suicidal equivalents, and 17 suicidal attempts of a total of 27 cases. 2 died as a result of suicide [35]. Gregory and co-workers [36] found out that 53\% thought about killing themselves and almost one-quarter either often (15\%), or very often (7\%) thought about killing themselves. A substantial proportion reported to have actually attempted to kill themselves (36\%). These values were much higher than our study. Six (3.5\%), had plan to take their lives, while $164(96.5 \%)$, were still optimistic. This is of statistical importance ( $\mathrm{p}$-value $=$ 0.03). In Nigeria, Chikezie and colleagues [12] while studying suicidality among PLWAs in Benin City found out that (34.7\%) expressed suicidal ideation, while $9.3 \%$ attempted suicide. Similar to this study, the commonest type of attempt was the use of pesticides and anti-malaria overdose.

Social Cohesion was very low in both males and females, 21 (67.7\%) and $112(80.6 \%)$ respectively among the depressed HIV patients. Only $2(6.5 \%)$ males had high social cohesion. This was statistically significant. This was similar to the findings of Starace [14] in his study, suicidal behaviours, enthanasia and AIDS where he concluded that PLWAs who attempted suicide were more likely to experience social isolation and lack social support. Twenty-two (70.9\%) males and $62(44.6 \%)$ females had one or two negative live events whereas 9 (29.1\%) males and $45(32.3 \%)$ females respondents had more than three negative life events. This is of statistical importance. A positive HIV diagnosis may be viewed by some as a negative life event resulting in, among others, marital problems, financial problems, stigmatization by family, friends and community, fear of disclosure of a positive HIV test result, problems in accessing health care, and other difficulties [1]. The majority of the HIV-positive patients in this study felt that the future seemed dark to them, irrespective of whether or not they had suicidal ideation.

\section{Limitations}

There are few limitations of the study that may reduce the generalization of our findings. The relatively small sample may be a potential limitation, but its calculation, estimated this number as sufficient to detect depression rates difference between asymptomatic and symptomatic HIV/AIDS patients. Furthermore like all cross-sectional studies, it is difficult to establish causal association between dependent and independent variables. Moreover, predetermined values for suicidal ideation, as depicted by the measuring instrument utilized, were used. For a more comprehensive suicide risk assessment, additional variables should be included such as, history of previous suicidal behaviour, a family history of suicidal behaviour, a pre-existing history of mood/or other psychiatric disorders, alcohol or drug abuse, and related socio-demographic factors. Moreover, because of the nature of the design, the relationship between sero-positivity, hopelessness, depression and an ultimate suicide attempt could not be assessed. Use of a single question item to assess suicidal ideation is another limitation our study. Further research should use more comprehensive measures to assess the frequency, duration and extent of suicidal thoughts in PLWAs. 


\section{Recommendation}

During the initial evaluation of the new patients, the physician should ask about a history of psychiatric disorders. The patient should be asked about history of suicidal ideation and suicide attempts. Similarly, all new patients should be screened for alcohol abuse using the CAGE questionnaire [15]. Any patient who shows evidence of depressed mood, anxiety of substance abuse should be asked about recent stressors and suicidal ideation and undergo a full evaluation for the presence of depression.

In addition to questions about duration and onset of suicidal ideation, question should also be posed about the lethality of the patient's intent and furtherance of plans. They should also discuss with patients the reasons why they think about suicide and should develop a plan to modify risk factors. Moreover, they should also refer patients who express chronic wishes to harm self or others for a comprehensive outpatient mental health evaluation and then maintain ongoing communication with the mental health provider(s) involved in the patients' mental health care.

\section{References}

[1] Gelder, M., Gath, D. and Mayou, R. (1984) Oxford Text-Book of Psychiatry. 2nd Edition, American Psychiatry Association, 478-506.

[2] Marzuk, P.M. (1991) Suicidal Behaviour and HIV Illnesses. International Review of Psychiatry, 3, 365-371. http://dx.doi.org/10.3109/09540269109072143

[3] Nwosu, S.O. and Odesanmi, W.O. (2001) Pattern of Suicide in Ile-Ife, Nigeria. West African Journal of Medicine, 20, 259-262.

[4] Zimmerman, M., Lis, J.D., Lush, D.T., Faber, N.J., Plescia, G. and Kuzma, M.A. (1995) Suicidal Ideation among Urban Medical Outpatients. Journal of General Internal Medicine, 10, 573-576. http://dx.doi.org/10.1007/BF02640368

[5] Murad, M.K. (2005) Suicide Prevention and Developing Countries. Journal of the Royal Society of Medicine, 98, 459463. http://dx.doi.org/10.1258/jrsm.98.10.459

[6] Carolina, M.S., Jose, M.B. and Yuan, P.W. (2005) Epidemiology of Suicide in Brazil. Characterization of Age and Gender Rates of Suicide. Revista Brasileira de Psiquiatria, 27, 1-8.

[7] Cooper-Patrick, L., Crum, R.M. and Ford, D.E. (1994) Identifying Suicidal Ideation in General Medical Patients. JAMA, 272, 1757-1762. http://dx.doi.org/10.1001/jama.1994.03520220051030

[8] Perry, S.W. (1994) HIV-Related Depression. Res Publ Assoc Res Nerv Ment Dis, 72, 223-228

[9] Schlebusch, L. (2005) Suicidal Behaviour in South Africa. University of Kwazulu-Natal Press, Pietermaritzburg.

[10] Marzuk, P.M., Tardiff, K. and Leon, A. (1997) HIV Sero-Prevalence among Suicide Victims in New York City. 19911993. American Journal of Psychiatry, 154, 1720-1725.

[11] McKgney, F.P. and O'Dowd, M.A. (1992) Suicidality and HIV Status. American Journal of Psychiatry, 149, $396-398$.

[12] Chikezie, U.E., Otakpor, A.N., Kuteyi, O.B. and James, B.O. (2012) Suicidality among Individuals with HIV/AIDS in Benin City, Nigeria: A Case-Control Study. AIDS Care, 24, 843-845. http://dx.doi.org/10.1080/09540121.2011.645008

[13] Alfonso, C.A., Cohen, M.A. and Aldajem, A.D. (1994) HIV Sero-Positivity as a Major Risk Factor for Suicide in the General Hospital. Psychosomatics, 35, 368-373. http://dx.doi.org/10.1016/S0033-3182(94)71758-8

[14] Starace, F. and Sherr, L. (1998) Suicidal Behaviour, Euthanasia, and AIDS. AIDS, 12, 339-347. http://dx.doi.org/10.1097/00002030-199804000-00001

[15] Flaving, D.K., Franklin, J.E. and Frances, R.J. (1986) The Acquired Immune Deficiency Syndrome (AIDS) and Suicidal Behaviour in Alcohol-Dependent Homosexual Men. American Journal of Psychiatry, 143, 1440-1442.

[16] Seth, C., Timothy, H., Ariene, K., Kathleen, M.S.W. and Berghoite, J.O. (2011) Depression and Thought of Suicide among Middle-Aged and Older Persons Living with HIV/AIDs. Journal Behavioural Medicine, 34, 102-111

[17] Kallichman, S.C., Heckman, T., Kochman, A., Sikkema, K. and Bergholte, J. (2000) Depression and Thoughts of Suicide among Middle-Aged and Older Persons Living with HIV/AIDS. Psychiatric Services, 51, 903-907. http://dx.doi.org/10.1176/appi.ps.51.7.903

[18] Gali, B.M., Na'aya, H.U. and Adamu, S. (2004) Suicide Attempts in HIV/AIDS Patient: Report of Two Cases Presenting with Penetrating Abdominal Injuries. Nigerian Journal of Medicine, 13, 407-409.

[19] Fawcett, J., Clark, D.C. and Busch, K.A. (1993) Assessing and Treating the Patient at Risk for Suicide. Current Psychiatry, 23, 244-255.

[20] Rosengard, C. and Folkman, S. (1997) Suicidal Ideation, Bereavement, HIV Serostatus and Psychosocial Variables in 
Patients of Men with AIDS. AIDS Care, 9, 373-384.

[21] Araoye, M.O. (2003) Data Collection. In: Research Methodology with Statistics for Health and Social Sciences, Nathadex Publishers, Ilorin, 130-159.

[22] Ndu, A.C., Arinze, S.U., Aguwa, E.N. and Obio, I.E. (2011) Prevalence of Depression and Role of Support Group in Its Management: A Study of Adult HIV/AIDS Patients Attending HIV/AIDS Clinic in a Tertiary Health Facility in South-Eastern Nigeria. Journal of Public Health and Epidemiology, 3, 182-186.

[23] Kapla, A. and Saddock, B.J. (2003) Synopsis of Psychiatry. 9th Edition, Lippincott Williams and Willkins, Philadephia, 375.

[24] Sharp, L.K. and Lipsky, M.S. (2002) Screening for Depression across the Life Span: A Review of Measures for Use in Primary Care Settings. American Family Physician, 66, 1001-1008.

[25] Liang, Y., Gong, T.H., Gong, Y.H., Wen, X.P., Guan, C.P., Li, M.C., Yin, P. and Wang, Z.Q. (2012) Social Determinants of Health and Depression: A Preliminary Investigation from Rural China. PLoS ONE, 7, Article ID: e30553.

[26] Word Health Organization (WHO) (2008) A Closing the Gap in a Generation: Health Equity through Action of on the Social Determinants of Health. http://www.searo.who.int/LinkFiles/SDH SDH FinalReport.pdf

[27] World Health Organization (WHO) (2010) A Comceptual Framework for Action on the Social Determinants of Health. http://whqlibdoc.who.int/publications/20109789241500852_eng.pdf

[28] Stewart, D.E. (2007) Social Determinants of Women's Mental Health. Journal of Psychosomatic Research, 63, 223224. http://dx.doi.org/10.1016/j.jpsychores.2007.07.002

[29] Pence, B., Reil, S., Whetten, K., Leserman, J., Stangl, D., Swartz, M., et al. (2007) Minorities, the Poor and Survivors of Abuse. HIV-Infected Patients in the US. Deep South. Southern Medical Journal, 100, 1114-1122.

[30] Asch, S.M., Kibourne, A.M., Gifford, A.L., Burnam, M.A., Turner, B., Shapiro, M.F. and Bozzette, S.A. for the HCSUS Consortium (2003) Under Diagnosis of Depression in HIV. Journal of General Internal Medicine, 18, 450-460. http://dx.doi.org/10.1046/j.1525-1497.2003.20938.x

[31] Beck, A.T., Steer, R.A., Kovacs, M. and Garrison, B. (1985) Hopelessness and Eventual Suicide: A 10-Years Prospective Study of Patients Hospitalized with Suicidal Ideation. American Journal of Psychiatry, 142, 559-563.

[32] Haller, D.L. and Miles, D.R. (2003) Suicidal Ideation among Psychiatric Patient with HIV: Psychiatric Morbidity and Quality of Life. AIDS and Behavior, 7, 101-108. http://dx.doi.org/10.1023/A:1023985906166

[33] April, C. and Courtney, M. (2011) Depression Is Common in People with HIV AIDS. The AIDS Beacons, 7, 1-3.

[34] Chandre, P.S., Ravi, V., Desai, A. and Subbakrishna, D.K. (1998) Anxiety and Depression among HIV-Infected Homosexuals. A Report from India. Journal of Psychosomatic Research, 45, 401-409. http://dx.doi.org/10.1016/S0022-3999(98)00028-2

[35] Carvajai, N.J., Vicioso, C., Santamaria, J.M. and Bosco, A. (1995) AIDS and Suicide Issues in Spain. AIDS Care, 7, 135-138. http://dx.doi.org/10.1080/09540129550126128

[36] Gregory, A., Amenla, N., Luke, S., Shalini, S., Anthony, F.J. and Michelle, K. (2013) Quality of Life, Depression, Anxiety and Suicidal Ideation among Men Who Inject Drug in Delhi, India. BMC Psychiatry, 13, 151. http://dx.doi.org/10.1186/1471-244X-13-151 


\section{Appendix A}

The Patient Health Questionnaire-9 (PHQ-9).

Over the last 2 weeks, how often have you been bothered by any of the following problems?

\begin{tabular}{|c|c|c|c|}
\hline Not at all & Several days & $\begin{array}{l}\text { More than } \\
\text { half the days }\end{array}$ & $\begin{array}{c}\text { Nearly } \\
\text { every day }\end{array}$ \\
\hline 0 & 1 & 2 & 3 \\
\hline 0 & 1 & 2 & 3 \\
\hline 0 & 1 & 2 & 3 \\
\hline 0 & 1 & 2 & 3 \\
\hline 0 & 1 & 2 & 3 \\
\hline 0 & 1 & 2 & 3 \\
\hline 0 & 1 & 2 & 3 \\
\hline 0 & 1 & 2 & 3 \\
\hline 0 & 1 & 2 & 3 \\
\hline \multicolumn{4}{|c|}{ Add columns: } \\
\hline 0 & + & + & + \\
\hline & & \multicolumn{2}{|c|}{ = Total Score: } \\
\hline
\end{tabular}

1. Little interest or pleasure in doing things

2. Feeling down, depressed, or hopeless

3. Trouble falling or staying asleep, or sleeping too much

4. Feeling tired or having little energy

5. Poor appetite or overeating

6. Feeling bad about yourself-or that you are a failure or have let yourself or your family down

7. Trouble concentrating on things, such as reading the newspaper or watching television

Moving or speaking so slowly that other people could have noticed, or the

8. opposite-being so fidgety or restless that you have been moving around a lot more than usual

9. Thoughts that you would be better off dead, or of hurting yourself in some way.

$$
\text { Total Score: }
$$

Scoring: 1 - 4: Minimal depression; 5 - 9: Mild depression; 10 - 14: Moderate depression; 15 - 19: Moderately severe depression; 20 - 27: Severe depression.

\section{Appendix B}

THE VARIABLES OF SOCIAL DETERMINANTS OF HEALTH [26-28]

SELF REPORTED ECONOMIC STATUS OF FAMILY

Poor Average Good

YEARS OF SCHOOLING

Below average ( 0 year) Average 1 - 6 years Above average 7 years and above

SOCIAL COHESION

Low 1-2 points Fair 3-5 points High $6-9$ points

NEGATIVE LIFE EVENTS

$\begin{array}{llll}> & 2 & 1 & 0\end{array}$ 